\title{
Sensitive Detection of SARS Coronavirus RNA by a Novel Asymmetric Multiplex Nested RT-PCR Amplification Coupled With Oligonucleotide Microarray Hybridization
}

\author{
Zhi-wei Zhang, Yi-ming Zhou, Yan Zhang, Yong Guo, Sheng-ce Tao, \\ Ze Li, Qiong Zhang, and Jing Cheng
}

\section{Summary}

We have developed a sensitive method for the detection of specific genes simultaneously. First, DNA was amplified by a novel asymmetric multiplex PCR with universal primer(s). Second, the 6-carboxytetramethylrhodamine (TAMRA)-labeled PCR products were hybridized specifically with oligonucleotide microarrays. Finally, matched duplexes were detected by using a laser-induced fluorescence scanner. The usefulness of this method was illustrated by analyzing severe acute respiratory syndrome (SARS) coronavirus RNA. The detection limit was $10^{\circ}$ copies $/ \mu \mathrm{L}$. The results of the asymmetric multiplex nested reverse transcription-PCR were in agreement with the results of the microarray hybridization; no hybridization signal was lost as happened with applicons from symmetric amplifications. This reliable method can be used to the identification of other microorganisms, screening of genetic diseases, and other applications.

Key Words: Polymerase chain reaction (PCR); multiplex PCR; asymmetric PCR; universal primer; severe acute respiratory syndrome (SARS) coronavirus; microarray.

\section{Introduction}

Multiplex Polymerase chain reaction (PCR) was designed to amplify multiple target sequences using more than one pair of primers in the reaction. It has the potential to save a considerable amount of time and effort without compromising test utility and additional instruments.

Since its first report in 1988 (1), multiplex PCR has become a rapid and convenient screening procedure in both clinical and research laboratories. It has been successfully applied to gene deletion analysis (2), mutation and polymorphism analysis (3), mRNA quantitative analysis $(4)$, RNA detection $(5,6)$ and 
genome sequencing (7). For infectious disease diagnosis, multiplex PCR has been a valuable tool for the identification of viruses $(8,9)$, bacteria $(10,11)$, parasites (12), and bacterial drug-resistance genes $(13,14)$.

The development of an efficient multiplex PCR protocol usually requires careful design of primers and many rounds of optimization. The common problems encountered in multiplex PCR are spurious amplification products, uneven or no amplification of some target sequences, and difficulties in reproducing the results. A successful multiplex PCR assay needs the following parameters to be set properly: relative concentration of the primers, concentration of the PCR buffer, balance between the magnesium chloride and dNTP concentrations, cycling temperatures, and amount of template and DNA polymerase. An optimal combination of annealing temperature and buffer condition is essential to ensure high specificity of multiplex PCR. Magnesium chloride concentration needs to be proportional to the amount of dNTPs. Adjusting primer concentration for each target sequence is also essential $(15,16)$. Henegariu et al. (17) presented a step-by-step protocol for multiplex PCR, after study, of some of these factors.

Preferential amplification of one target sequence over another (bias in templateto-product ratios) is a known phenomenon in multiplex PCR; it mainly occurs because multiplex PCR has a limited supply of enzymes and nucleotides. All primer pairs compete for the same pool of supplies, but their amplification efficiencies are different. Amplification biases that were strongly dependent on the primers and, to a lesser degree, the templates, have been described (17).

We have developed a new strategy for the optimization of multiplex PCR to overcome the problem of preferential amplification of one target sequence over another. Two universal sequences irrelevant to the targets were added to the $5^{\prime}$ termini of the specific primers. The extra universal primers, whose sequences were identical with the ones added into the specific primers, were used in the multiplex PCR reaction together (Fig. 1A). Ideally, the universal primers can reduce the amplification biases of multiplex PCR, so the optimization of multiplex PCR becomes much easier than before (18).

Asymmetric PCR is often used to generate single-stranded DNA (ssDNA). The method is especially useful for hybridizing PCR product against probes such as the ones used in microarray hybridizations. Oligonucleotide microarray has provided a powerful platform for nucleic acid analysis (19-22). Hybridization of labeled nucleic acid targets with microarrays of surfaceimmobilized oligonucleotide probes was the central event in the detection of nucleic acids on microarrays (23). Before hybridization, the ssDNA targets were prepared by using denaturation of the PCR products or by other methods. Only one of the two DNA strands was available for hybridization with the immobilized probes; the other one competed with the probes for the target and therefore was regarded as the interfering strand (24). What was worse was that 


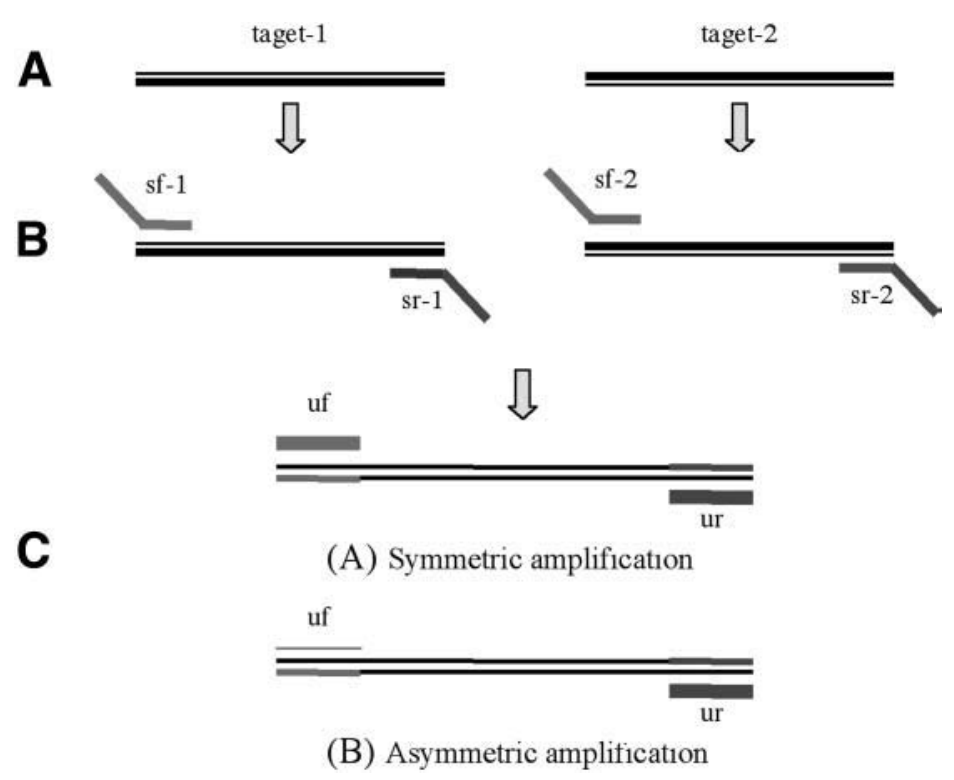

Fig. 1. Schematic representation of the multiplex PCR used in this work. (a), Targets for amplification. Only two targets are shown here. (b), Gene-specific primer amplifications, which are the same as ordinary PCR except that two different universal sequences irrelevant to the targets were added to the $5^{\prime}$ end of the specific primers. (c), Universal primer amplification. In this reaction, the amplicons of the gene-specific primers served as templates. sf, the forward gene-specific primer; sr, the reverse genespecific primer; uf, the forward universal primer; ur, the reverse universal primer. All primers are added to one tube. (A) For symmetric amplification, uf and ur are used with equal molar amounts. (B) For asymmetric PCR, the uneven primers uf and ur were used, and in some cases uf was even absent from the reactions.

the annealing effect of the two complementary strands was dominant, because of their faster kinetics and higher thermodynamic stabilities. Kawai et al. (25) reported that the sensitivity with ssDNA targets was fivefold higher than that with boiled double-stranded DNA (dsDNA) targets, when they were hybridized with oligonucleotide probes. Thus preparation of ssDNA targets was preferred for high efficient hybridization on oligonucleotide microarrays.

In the conventional asymmetric PCR for ssDNA preparation, the two primers are present in different molar amounts. When the primer in the limited amount is exhausted, an excess of ssDNA will be produced in each cycle (26). Erdogan et al. (27) have successfully applied the single-stranded targets produced by asymmetric PCR to a single-nucleotide polymorphism detection system. However, they considered this method to have the disadvantage that the products appeared as a serious smear of bands in agarose gel (27). To improve the 
ssDNA production efficiency of this method, Kaltenboeck et al. (28) designed a two-step asymmetric PCR, in which a symmetric PCR for dsDNA was first preformed under optimal conditions, and then a single primer was used to generate ssDNA targets by using the purified double-stranded PCR products as template. Although it was time consuming, this two-step method was still applied to ssDNA target preparation (28-30).

However, the conditions are extraordinarily involved in ordinary multiplex PCR, if the asymmetric PCR is performed in a parallel fashion in the same reaction. There are few references for asymmetric multiplex amplification. This issue may be simplified by modifying the universal primer-mediated multiplex PCR using disproportional universal primers (Fig. 1B).

Severe acute respiratory syndrome (SARS) is a new infectious disease of humans, first recognized in late February 2003 in Hanoi, Vietnam. The disease spread rapidly, with cases reported from 29 countries on five continents over 4 months (31-38). By July 3, 2003, this epidemic had resulted in 8439 reported cases globally, of which 812 were fatal (http://www.who.int/csr/sars/country/ 2003 _07_03). Rapid and sensitive laboratory confirmation of SARS coronavirus $(\mathrm{CoV})$ infection was important for managing patient care and for preventing nosocomial transmission. Although serological testing was reliable as a retrospective diagnostic method, diagnosis of the infection in the early phase of the illness was important for patient care.

In this study, SARS CoV RNA was amplified by using multiplex nested reverse transcription-PCR (RT-PCR), followed by microarray hybridization. During the multiplex PCR, several different ratios of the universal primers were used, and the results were compared.

\section{Materials}

1. Oligonucleotide primers (Sangon, Shanghai, China).

2. Oligonucleotide probes (Sangon).

3. Oligonucleotide microarray (CapitalBio, Beijing, China).

4. SARS CoV RNA (provided by Professor Tao Hung at the Virological Institute, Chinese Center for Disease Control and Prevention).

5. Normal human total RNA (TW-Times, Beijing, China).

6. Roche LightCycler system (Roche, Mannheim, Germany).

7. RealArt HPA-CoV LC RT Reagents (Artus, Hamburg, Germany).

8. One-step RT-PCR kit (TaKaRa, Dalian, Liaoning, China).

9. PTC-225 thermal cycler (MJ Research, Miami, FL).

10. $2 \mathrm{X}$ Master mixture (TW-Times).

11. Deoxyuridine triphosphate (dUTP, Sangon).

12. Uracil-DNA glycosylase (Invitrogen, Carlsbad, CA).

13. Mineral oil (Sigma).

14. DL2000 DNA molecular weight marker (TaKaRa). 
15. UVP system (Ultraviolet Products, Cambridge, UK).

16. AminoSlide $\mathrm{TM}^{\mathrm{TM}}$ slide (CapitalBio).

17. SARSarray ${ }^{\mathrm{TM}}$ slide (CapitalBio).

18. HybriCassettes ${ }^{\mathrm{TM}}$ (CapitalBio).

19. SmartCover ${ }^{\mathrm{TM}}$ (CapitalBio).

20. Dimethyl sulfoxide (DMSO).

21. GenePix 4000B (Axon, Union City, CA).

22. Hybridization solution: 5.6X standard saline citrate (SSC), 9.1X Denhart's solution, $0.36 \%$ sodium dodecyl sulfate (SDS), $50 \mathrm{n} M$ of probe 127; make fresh as required.

23. Washing solution A: $2 X$ SSC and $0.2 \%$ SDS.

24. Washing solution B: 0.2X SSC.

\section{Methods}

The methods described below outline (1) the construction of the microarray; (2) the quantification and dilution of SARS CoV RNA; (3) the multiplex nested RT-PCR amplification, symmetric and asymmetric; (4) the agarose gel electrophoresis; (5) the microarray hybridization; and (6) the fluorescence scanning.

\subsection{Microarray}

An overlapping of 70-nucleotide (nt) segment with the $T_{\mathrm{m}}$ value set at $88^{\circ} \mathrm{C}$ and with the least free energy in the hairpin structure and dimer was designed as the probe following the rule from http://www.westburg.nl/download/arrayposter.pdf to minimize cross-hybridization. To increase the immobilization efficiency of the probes, 10 thymidines were added to the $5^{\prime}$ end of each probe.

After an initial screening test, four oligonucleotides were chosen as the probes for identifying SARS CoV (probes 11, 24, 40, and 44). Additionally, several probes were also included for control purposes. The quality control (QC) probe was used to confirm the efficiency of the attachment chemistry on the surface of the substrate. For all tests, this probe always generates a strong and consistent fluorescence signal. The internal control (IC) probe, which hybridizes to the amplicons of its inner primers, was designed to guarantee that the entire nested RT-PCR process operates as expected. The external control (EC) probe was used to monitor the efficiency of the hybridization process. The negative control (NC) probe was an oligonucleotide whose sequence was irrelevent to any amplicons of the multiplex nested RT-PCR. The blank control (BC) probe was DMSO spotted on the substrate, to ensure that no signal is detected on these spots, indicating no carryover of the previously spotted samples. The sequence information of the probes is listed in Table 1.

The probes were suspended in 50\% DMSO at a concentration of $10 \mu \mathrm{M}$ and printed on glass slides modified with amino groups (AminoSlide). Four subarrays 


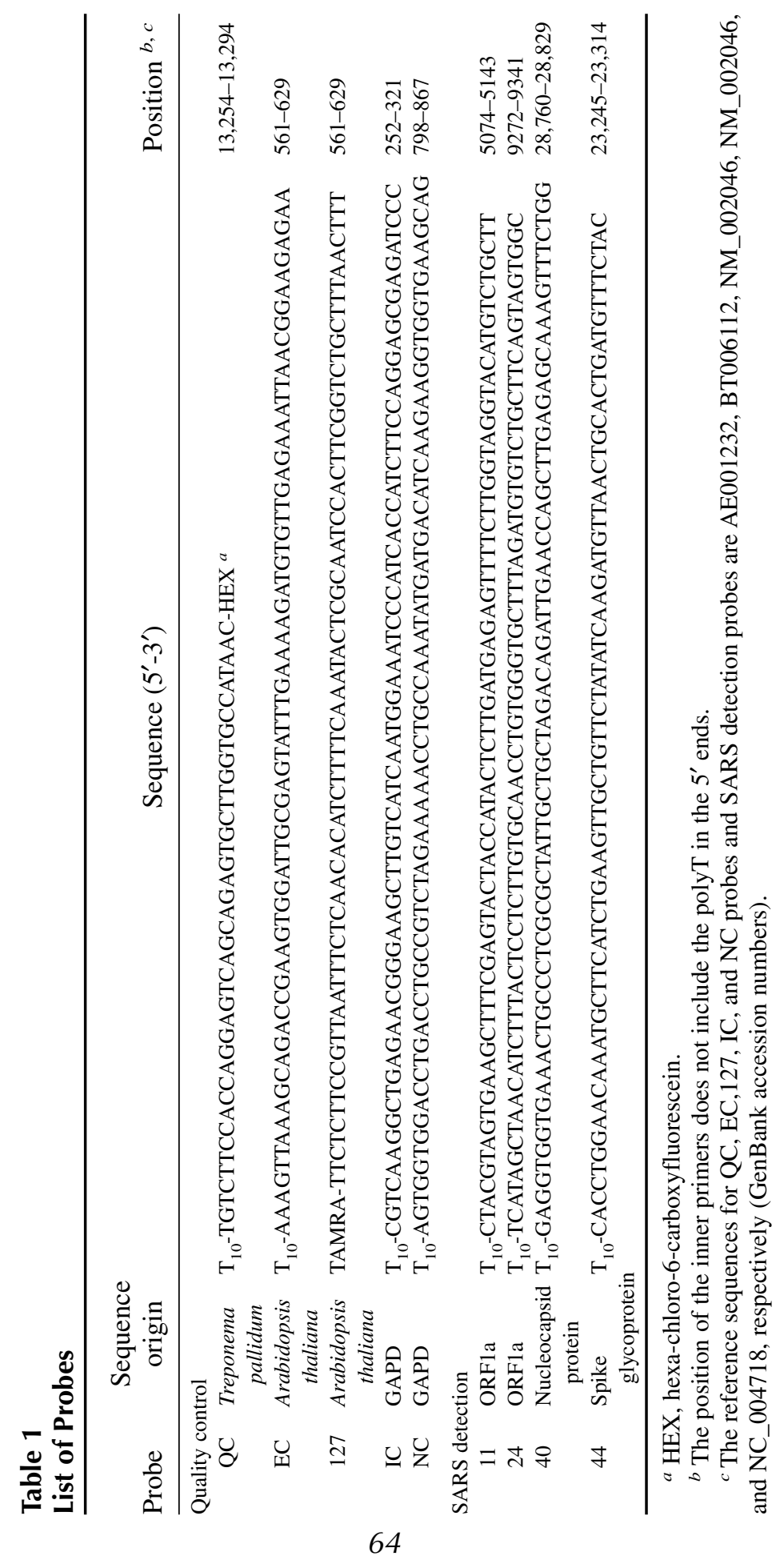




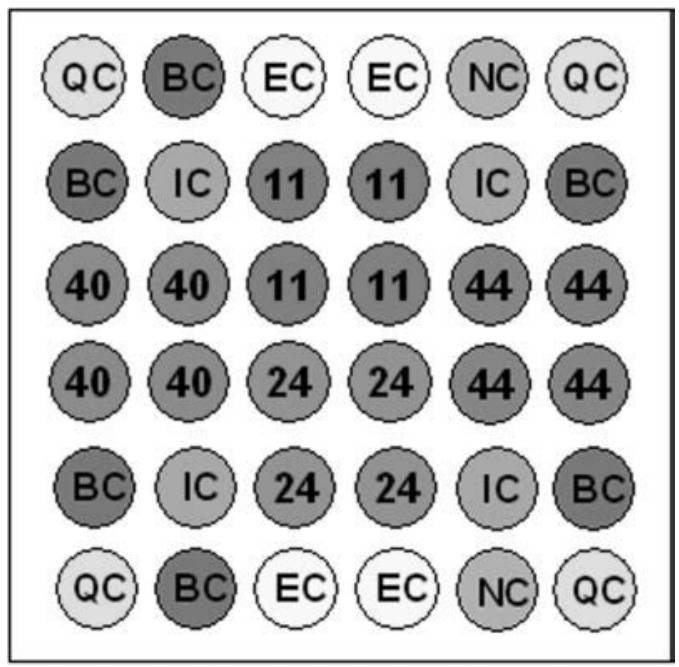

Fig. 2. The illustration of the microarray designed for detection of SARS CoV. BC, DMSO spotted as blank control; QC, Hex-labeled oligonucleotide used for quality control of surface chemistry; IC, internal control probe for nested RT-PCR and hybridization; EC, external control probe for hybridization; NC, negative control probe for hybridization; 11 and 24, probes selected from SARS CoV's ORF 1a; 40, probe selected from the ORF of SARS CoV for nucleocapsid protein; 44, probe selected from the ORF of SARS CoV for spike glycoprotein.

of the $6 \times 6$ probes were printed on each slide. The design of the microarray is illustrated in Fig. 2.

\subsection{SARS COV RNA}

\subsubsection{Quantification of the SARS COV RNA}

Real-time RT-PCR was performed to quantify the virus RNA on a Roche LightCycler system using RealArt HPA-CoV LC RT Reagents. The result is shown in Fig. 3. The quantification standards (a-d) were $10^{1}, 10^{2}, 10^{3}$, and $10^{4}$ copies/ $\mu \mathrm{L}$ SARS viral RNA, respectively. Between the log concentration of quantification standards and their crossing points, a regression curve has been drawn but not shown $(r=-1.00)$. According to the curve, the concentration of the sample RNA was $10^{3}$ copies $/ \mu \mathrm{L}$. In Fig. 3, we can see that the curve of the sample RNA (s) almost overlaps the curve of quantification standard (c). Because the sample RNA has been diluted $10^{5}$ times before quantification, the concentration of the original RNA is approx $10^{8}$ copies $/ \mu \mathrm{L}$. 


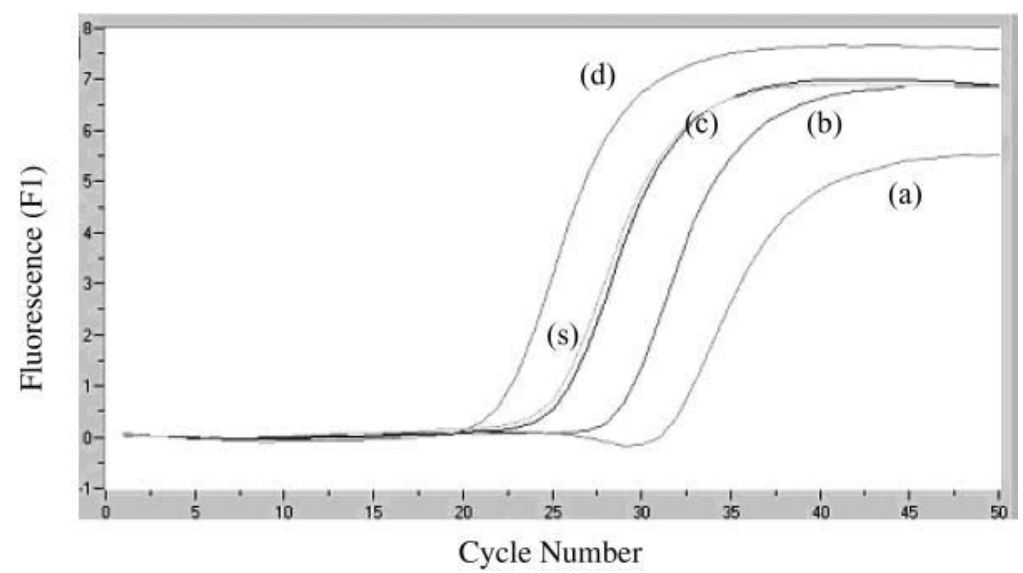

Fig. 3. Quantitative analysis of SARS CoV RNA by means of real-time RT-PCR. (a-d), quantification standards (HPA-CoV LC QS 1-4) supplied within the kit by the manufacturer. Concentrations of SARS virus RNA in (a-d) are $10^{1}, 10^{2}, 10^{3}$, and $10^{4}$ copies $/ \mu \mathrm{L}$, respectively. (s), sample for quantification. Before real-time RT-PCR, the SARS viral RNA for quantification was diluted $10^{5}$ times.

\subsubsection{Dilution of the SARS COV RNA}

1. The normal human total RNA (TW-Times) was spiked into the SARS CoV RNA. The RNA mixture was prepared by mixing equal amounts of viral RNA $\left(10^{5}\right.$ copies $/ \mu \mathrm{L})$ and human total RNA $(16.7 \mu \mathrm{g} / \mu \mathrm{L})$.

2. The mixture was then 10 -fold diluted continuously with diethyl pyrocarbonate (DEPC)-treated deionized water and served as templates for subsequent amplification.

\subsection{Multiplex Nested RT-PCR}

\subsubsection{Primers (See Note 7)}

1. Sequence data for SARS CoV were obtained from the curated database in GenBank. The unique and conserved regions of SARS CoV were selected by aligning the released SARS CoV sequences and the latest nonredundant nucleic acid sequences in the NCBI database (ftp://ftp.ncbi.nih.gov).

2. To allow detection of SARS $\mathrm{CoV}$, multiple regions from the open reading frame (ORF) of replicase 1a, spike glycoprotein, and nucleocapsid protein were selected as the targets for hybridization detection.

3. To amplify the four segments from these three ORFs in the genome of SARS CoV, four sets of outer and inner primers were designed, as listed in Table 1. The four outer primer sets were designed in the selected genes using Primer3 (39) by setting the optimal $T_{\mathrm{m}}$ to $67^{\circ} \mathrm{C}$ and the size of PCR product from 400 to $1200 \mathrm{bp}$. Two universal primers were allowed to bind to the $5^{\prime}$ end of the designed inner primers for efficient labeling of the PCR product. 
4. To perform nested PCR, the inner primer pair was designed to prime at the region that was approx 200 bp distant from both ends of each selected PCR product.

5. The primers were aligned using BLASTN with the latest nonredundant nucleic acid sequence database downloaded from the ftp site of the NCBI to avoid mispriming. The primers were aligned using BLASTN with all the SARS CoV genomes available to avoid mutations in the primers

6. The primers for amplifying the human glyceraldehyde-3-phosphate dehydrogenase (GAPD) gene from human RNA were designed as the internal control for monitoring the entire amplification process.

7. The universal primers were end-labeled with a fluorescent dye, 6-carboxytetramethylrhodamine (TAMRA; see Note 8). Primers information is given in Table 2.

\subsubsection{One-Step RT-PCR}

The first-round reaction of the nested RT-PCR is one-step RT-PCR. The secondround reaction is PCR using the products from the first round as the templates.

1. The one-step RT-PCR kit from TaKaRa was used for the first-round reaction, whose conditions were as follows. The total volume for each reaction was $10 \mu \mathrm{L}$ including 1X One Step RNA PCR buffer, $5 \mathrm{mM} \mathrm{MgCl} 2,0.8 \mathrm{U} / \mu \mathrm{L}$ RNase inhibitor, $0.1 \mathrm{U} / \mu \mathrm{L}$ AMV RTase XL, 0.1 U/ $\mu \mathrm{L}$ AMV-optimized Taq, $0.5 \mu M$ of all five pairs of outer primers, $1 \mathrm{mM}$ each dNTP, and $4.5 \mu \mathrm{L}$ RNA mixture (the SARS CoV RNA concentration was $10^{3}, 10^{2}, 10^{1}$, and $10^{\circ}$ copies $/ \mu \mathrm{L}$, respectively), or $4.5 \mu \mathrm{L}$ DEPC-treated deionized water as the blank control and $4.5 \mu \mathrm{L}$ of human total RNA as the negative control.

2. Mineral oil $(20 \mu \mathrm{L})$ was added to cover the reaction fluid.

3. The reactions were performed on a PTC-225 thermal cycler. The thermal conditions were as follows: 1 cycle at $50^{\circ} \mathrm{C}$ for $30 \mathrm{~min} ; 1$ cycle at $94^{\circ} \mathrm{C}$ for $3 \mathrm{~min} ; 30$ cycles at $94^{\circ} \mathrm{C}$ for $30 \mathrm{~s}, 55^{\circ} \mathrm{C}$ for $30 \mathrm{~s}$, and $72^{\circ} \mathrm{C}$ for $1 \mathrm{~min} ; 1$ cycle at $72^{\circ} \mathrm{C}$ for $10 \mathrm{~min}$.

\subsubsection{Nested PCR, Symmetric and Asymmetric}

1. During the RT-PCR reaction, the reaction mixture for the second-round nested PCR was prepared. A $2 \mathrm{X}$ master mixture was used, and the conditions were as follows. The total volume for each mixture was $40 \mu \mathrm{L}$, including $1.25 \mathrm{X}$ master mixture, extra $2.5 \mu \mathrm{M} \mathrm{MgCl}_{2}, 0.5 \mathrm{~m} M \mathrm{dUTP}, 0.0125 \mathrm{U} / \mu \mathrm{L}$ uracil-DNA glycosylase, $0.25 \mu M$ inner primers, and $1.25 \mu M$ universal reverse primer (ur). For the universal forward primer (uf), four different concentrations were used, including 1.25, 0.05, 0.0125, and $0 \mu M$, so that the ratios of the primer uf to the ur were $1: 1,1: 25,1: 100$, and $0: 1$, respectively (see Notes 1-3, 9). These reaction mixtures were kept on ice before use.

2. After the RT-PCR reaction, the prepared reaction mixture of the nested PCR was added directly to the fluid of the first round, mixed well, and centrifuged briefly.

3. The PCR reaction was performed on a PTC-225 thermal cycler. Thermal conditions were as follows: 1 cycle at $37^{\circ} \mathrm{C}$ for $10 \mathrm{~min} ; 1$ cycle at $68^{\circ} \mathrm{C}$ for $10 \mathrm{~min} ; 1$ cycle at $94^{\circ} \mathrm{C}$ for $10 \mathrm{~min} ; 30$ cycles at $94^{\circ} \mathrm{C}$ for $30 \mathrm{~s}, 60^{\circ} \mathrm{C}$ for $30 \mathrm{~s}$, and $72^{\circ} \mathrm{C}$ for $1 \mathrm{~min}$; 1 cycle at $72{ }^{\circ} \mathrm{C}$ for $10 \mathrm{~min}$. 
Table 2

List of Primers

\begin{tabular}{|c|c|c|c|}
\hline Primers $^{a}$ & Sequence $\left(5^{\prime}-3^{\prime}\right)^{b}$ & Position ${ }^{c, d}$ & $\begin{array}{c}\text { Amplicon } \\
\text { size } \\
\text { (bp) }\end{array}$ \\
\hline \multicolumn{4}{|l|}{ Outer } \\
\hline 11-of & GCATCGTTGACTATGGTGTCCGATTCT & $4433-4459$ & 1071 \\
\hline 11-or & ACATCACAGCTTCTACACCCGTTAAGGT & $5476-5503$ & \\
\hline 24-of & GCTGCATTGGTTTGTTATATCGTTATGC & $8542-8569$ & 1097 \\
\hline 24-or & ATACAGAATACATAGATTGCTGTTATCC & $9611-9638$ & \\
\hline 40 -of & CCTCGAGGCCAGGGCGTTCC & $28,321-28,340$ & 634 \\
\hline 40 -or & CACGTCTCCCAAATGCTTGAGTGACG & $28,929-28,954$ & \\
\hline 44-of & TTAAATGCACCGGCCACGGTTTG & $23,001-23,023$ & 455 \\
\hline 44 -or & CCAGCTCCAATAGGAATGTCGCACTC & $23,430-23,455$ & \\
\hline IC-of & ATGGGGAAGGTGAAGGTCGG & $76-95$ & 310 \\
\hline IC-or & TGGTGAAGACGCCAGTGGAC & $366-385$ & \\
\hline \multicolumn{4}{|l|}{ Inner } \\
\hline 11-if & usf-AGCCGCTTGTCACAATGCCAATT ${ }^{b}$ & $4520-4542$ & 897 \\
\hline 11-ir & usr-CATCACCAAGCTCGCCAACAGTT ${ }^{b}$ & $5355-5377$ & \\
\hline 24-if & usf-TAGCCAGCGTGGTGGTTCATACAA & 8709-8732 & 836 \\
\hline 24-ir & usr-CTCCCGGCAGAAAGCTGTAAGCT & 9483-9505 & \\
\hline 40-if & usf-TCCTCATCACGTAGTCGCGGTAATTC & $28,678-28,703$ & 257 \\
\hline 40-ir & usr-GGCTTTTTAGATGCCTCAGCAGCA & $28,872-28,895$ & \\
\hline 44-if & usf-ATGCACCGGCCACGGTTTGTG & $23,005-23,025$ & 388 \\
\hline 44-ir & usf-ATGCGCCAAGCTGGTGTGAGTTGA & $23,330-23,353$ & \\
\hline IC-if & usf-CGTATTGGGCGCCTGGTCAC & $112-131$ & 275 \\
\hline IC-ir & usr-CCAGCATCGCCCCACTTGAT & $328-347$ & \\
\hline \multicolumn{4}{|l|}{ Universal } \\
\hline uf & TAMRA-tcacttgcttccgttgagg & l & l \\
\hline ur & TAMRA-ggtttcggatgttacagcgt & l & l \\
\hline
\end{tabular}

${ }^{a} \mathrm{o}$, outer primer; i, inner primer; f, forward primer; $r$, reverse primer; $\mathrm{u}$, universal primer; IC, inner control.

${ }^{b}$ usf, the forward universal sequence $5^{\prime}$-tcacttgcttccgttgagg- $3^{\prime}$; usr, the reverse universal sequence $5^{\prime}$-ggtttcggatgttacagcgt- $3^{\prime}$.

${ }^{c}$ The position of the inner primers does not include the universal sequences usf and usr.

${ }^{d}$ The reference sequence for SARS gene-specific primers and inner control primers are NC_004718 and NM_002046, respectively (GenBank accession numbers).

\subsection{Agarose Gel Electrophoresis}

1. A $1.5 \%$ agarose gel was prepared by melting $1.5 \mathrm{~g}$ of agarose in $100 \mathrm{~mL}$ of $1 \mathrm{X}$ TBE buffer. Ethidium bromide $(30 \mu \mathrm{g})$ was added to the agarose solution before it became solidified. 
(a)

(b)

(c)

(d)

$M \overline{123 \mathrm{NBI}} \overline{456 \mathrm{NBI}} \overline{789 \mathrm{~N} \text { BI }} \overline{101112 \mathrm{~N} \mathrm{BI} M}$
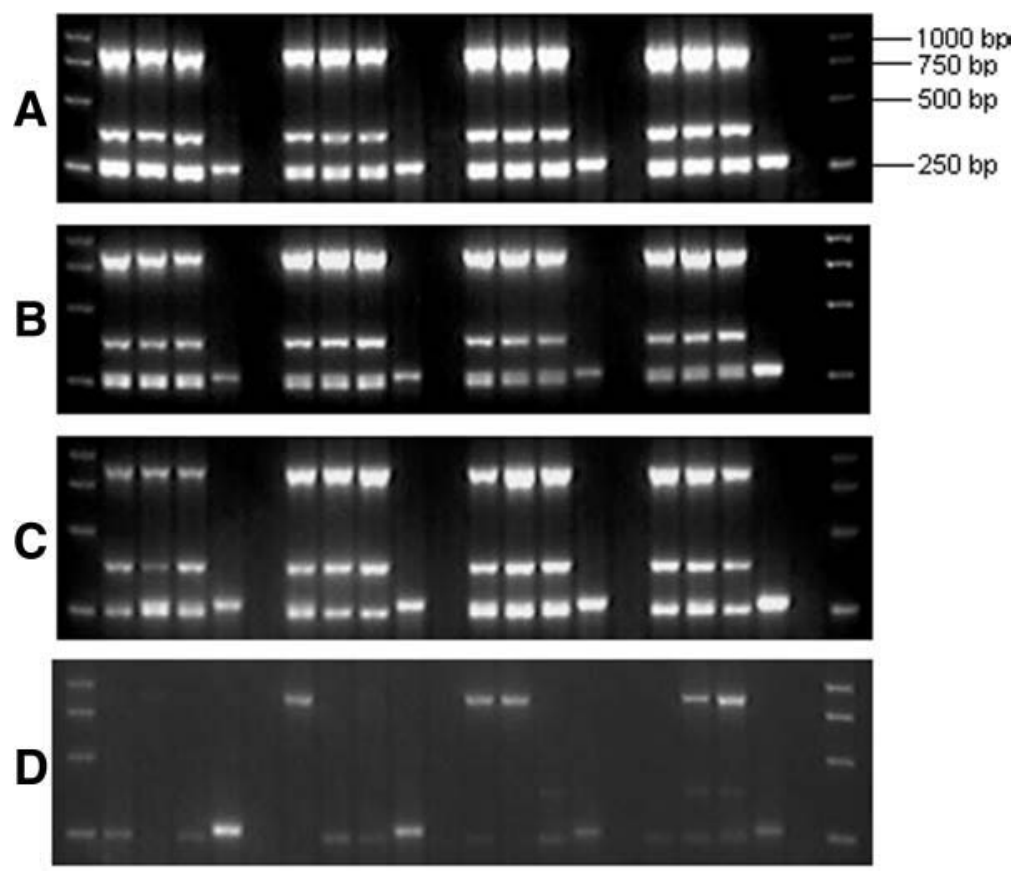

Fig. 4. Electrophoretic results of multiplex nested RT-PCR amplicons. (A-D), SARS CoV RNA and human total RNA at concentrations of $10^{3}, 10^{2}, 10^{1}$, and $10^{\circ}$ copies $/ \mu \mathrm{L}$ or $167,16.7,1.67$, and $0.167 \mathrm{ng} / \mu \mathrm{L}$ as the templates for RT-PCR in lanes 1-12 (three parallel reactions were performed). (a-d), Ratios of universal primers uf to ur were 1:1, 1:25, 1:100, and 0:1, respectively. Lane $\mathrm{M}$, molecular size marker; lane $\mathrm{N}$, negative control, for which the same reaction was performed but without the addition of the virus RNA; lane B1, blank control, in which reaction DEPC-treated $\mathrm{H}_{2} \mathrm{O}$ was used as the template. The arrow shows the visible amplicon ( $257 \mathrm{bp}$ ) for the pair of primers 40 in this reaction.

2. PCR products $(2 \mu \mathrm{L})$ were loaded onto the gel along with the DL2000 DNA molecular weight marker.

3. The gel was run at $8 \mathrm{~V} / \mathrm{cm}$ for $90 \mathrm{~min}$ and then photographed using a UVP system.

The electrophoretic results of the multiplex nested RT-PCR are shown in Fig. 4 (see Note 5). No band was seen in all blank controls (lanes Bl). A band of the predicted size (275 bp) was observed in all negative controls (lanes N). For other samples, it appeared that the asymmetric amplification was more efficient than the symmetric amplification (D). When the concentration of SARS viral RNA was $10^{\circ}$ copies $/ \mu \mathrm{L}$, the bands for the inner controls ( $275 \mathrm{bp}$ ) became invisible. The reason 
was that for the inner control template, the human total RNA spiked into the viral RNA was too little $(0.167 \mathrm{ng} / \mu \mathrm{L})$ to be amplified effectively. Similarly, only part of the bands for SARS CoV amplification was visible when the concentration of SARS viral RNA was $10^{\circ}$ copies/ $\mu$ L. However, when the higher concentrations of RNA were used as templates, the bands of three parallel multiplex nested RT$\mathrm{PCR}$ reactions were similar to each other, regardless of symmetric or asymmetric amplifications.

\subsection{Microarray Hybridization}

\subsubsection{Hybridization}

1. To prepare the hybridization sample, $6.8 \mu \mathrm{L}$ of the amplicon was added to $8.2 \mu \mathrm{L}$ of the hybridization solution. The mixture was centrifuged briefly.

2. To denature the dsDNA, the hybridization samples were heated at $95^{\circ} \mathrm{C}$ for $5 \mathrm{~min}$ followed by snap chilling on ice for $3 \mathrm{~min}$.

3. The SARSarray slide with four reaction wells was placed into the HybriCassettes preloaded with $200 \mu \mathrm{L}$ of double-distilled water to reduce the evaporation.

4. The SmartCover with four molded sample-loading holes was placed on top of the slide.

5. The denatured DNA samples were applied to the individual reaction well on the glass slide through the loading holes on the plastic cover.

6. The sealed cartridge was placed in a $67^{\circ} \mathrm{C}$ water bath for $2.5 \mathrm{hs}$.

\subsubsection{Washing}

1. When the hybridization was completed, the slide was removed from the cartridge, and the cover slip was removed.

2. The slide was washed sequentially in the prewarmed $\left(45^{\circ} \mathrm{C}\right)$ washing solution $A$ for $6 \mathrm{~min}$, (twice) followed by washing solution B for $6 \mathrm{~min}$, (twice). Afterward, the slide was rinsed in the double-distilled water and dried by centrifugation at $110 \mathrm{~g}$ for $2 \mathrm{~min}$.

\subsection{Fluorescence Scanning}

The slide was scanned using the GenePix 4000B. The scanning conditions were as follows: wavelength, $532 \mathrm{~nm}$; laser power, 33\%; pixel size, $10 \mu \mathrm{m}$; photomultiplier tube, 550 Vo; brightness, $90 \%$, and contrast, $90 \%$.

Part of the hybridization images is shown in Fig. 5. Every QC or EC probe was positive, and every $\mathrm{BC}$ or NC probe was negative in all hybridization images, indicating high-quality performance and excellent reproducibility. For the BC PCR, no hybridization signal was visible for the other probes, but the IC probe had a positive signal for the NC PCR. For SARS detection, the hybridization signal of probe 40 was always invisible when symmetric PCR was performed (a), although bands of amplicons with the right size (257 bp) were seen in Fig. 4. However, once the concentration of primer uf to primer ur was disproportional, hybridization signals were observed [(b), (c) or (d); see Notes 4-6]. 
(a)

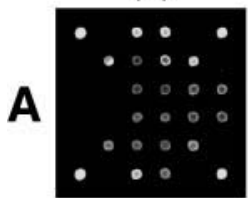

B
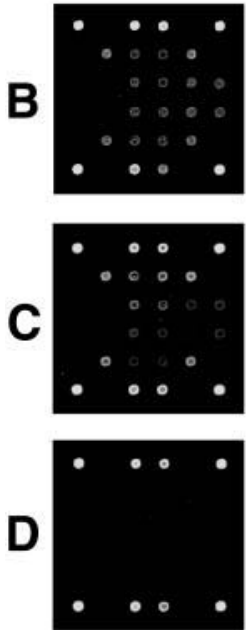

(b)
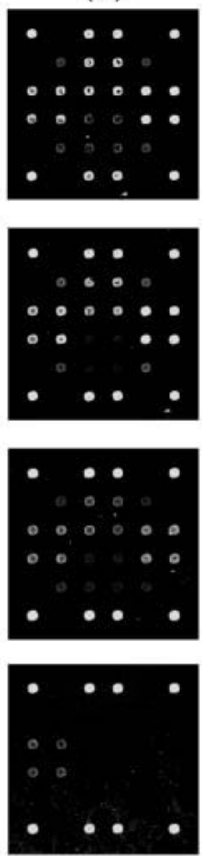

(c)
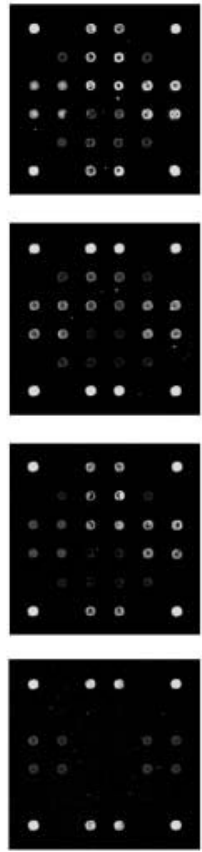

(d)
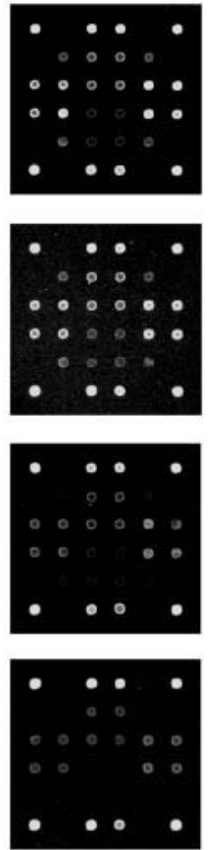
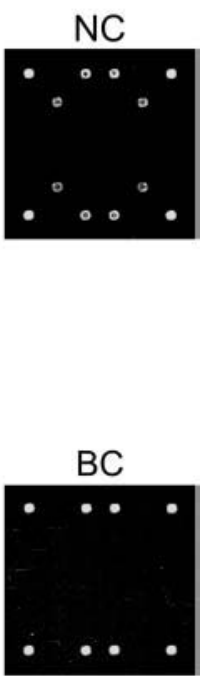

Fig. 5. Part of the hybridization results. (A-D), SARS CoV RNA and human total RNA at concentrations of $10^{3}, 10^{2}, 10^{1}$, and $10^{\circ}$ copies/ $\mu \mathrm{L}$ or $167,16.7,1.67$, and 0.167 $\mathrm{ng} / \mu \mathrm{L}$, respectively, were used as templates for RT-PCR. (a-d) In multiplex PCR the ratios of universal primers uf to ur were $1: 1,1: 25,1: 100$, and $0: 1$, respectively. In the three parallel multiplex nested RT-PCR reactions, only one hybridization image (lane 3, 6, 9, and 12 in Fig. 4) was shown. NC, negative control; BC, blank control. All NC (BC) had the same hybridization images, so only one is shown here. For probe 40, no hybridization signal was observed in (a), but signal was seen in (b-d).

All hybridization results of the SARS detection probes are shown in Table 3. From the table we can see that there was at least one SARS CoV-specific probe, whose hybridization result was positive in all cases for the asymmetric amplification, so its limit for SARS viral RNA detection should be $10^{0}$ copies $/ \mu \mathrm{L}$. For the symmetric amplification, because of the hybridization signal loss of probe 40 , the detection limit was 10 -fold less than that of asymmetric amplification, which was $10^{1}$ copies $/ \mu \mathrm{L}$. (See Notes 9-10.)

\section{Notes}

1. Preferential amplification of one target sequence over another is perhaps the biggest problem in multiplex PCR. This is mainly because multiplex PCR has a limited supply, such as the polymerase and the nucleotides, all primer pairs compete for them, and sometimes the amplification efficiency of one primer pair is 
Table 3

Recordings of Microarray Analyses of SARS Detection Probes ${ }^{a}$

\begin{tabular}{|c|c|c|c|c|c|c|c|c|c|c|c|c|c|}
\hline \multirow{2}{*}{$\begin{array}{l}\text { Concentration } \\
\text { of virus RNA } \\
\text { (copies/mL) }\end{array}$} & \multirow{2}{*}{$\begin{array}{c}\text { Probe } \\
\text { no }\end{array}$} & \multicolumn{3}{|c|}{ 1:1 } & \multicolumn{3}{|c|}{$1: 25$} & \multicolumn{3}{|c|}{ 1:100 } & \multicolumn{3}{|c|}{$0: 1$} \\
\hline & & 1 & 2 & 3 & 1 & 2 & 3 & 1 & 2 & 3 & 1 & 2 & 3 \\
\hline \multirow[t]{4}{*}{$10^{3}$} & 11 & + & + & + & + & + & + & + & + & + & + & + & + \\
\hline & 24 & + & + & + & + & + & + & + & + & + & + & + & + \\
\hline & 40 & - & - & - & + & + & + & + & + & + & + & + & + \\
\hline & 44 & + & + & + & + & + & + & + & + & + & + & + & + \\
\hline \multirow[t]{4}{*}{$10^{2}$} & 11 & + & + & + & + & + & + & + & + & + & + & + & + \\
\hline & 24 & + & + & + & + & + & + & + & + & + & + & + & + \\
\hline & 40 & - & - & - & + & + & + & + & + & + & + & + & + \\
\hline & 44 & + & + & + & + & + & + & + & + & + & + & + & + \\
\hline \multirow[t]{4}{*}{$10^{1}$} & 11 & + & + & + & + & + & + & + & + & + & + & + & + \\
\hline & 24 & + & + & + & + & + & + & + & + & + & + & + & + \\
\hline & 40 & - & - & - & + & + & + & + & + & + & + & + & + \\
\hline & 44 & + & + & + & + & + & + & + & + & + & + & + & + \\
\hline \multirow[t]{4}{*}{$10^{0}$} & 11 & - & + & - & + & - & - & + & + & - & - & + & + \\
\hline & 24 & - & - & - & - & - & - & - & - & - & - & - & - \\
\hline & 40 & - & - & - & - & + & + & + & - & + & + & + & + \\
\hline & 44 & - & - & - & - & - & - & - & - & + & - & + & + \\
\hline
\end{tabular}

${ }^{a}+$, positive hybridization signal; - , negative hybridization signal.

quite different from that of another. The most curious factor of multiplex PCR is the competition of the primers involved. The development of an efficient multiplex PCR requires strategic planning and multiple attempts to optimize the reaction conditions. Approaches have been reported with varying degree of success. For example, Shuber et al. (40) added an unrelated sequence to the $5^{\prime}$ end of the primers to reduce the differences in annealing efficiencies of different loci. Henegariu et al. (17) optimized the final concentration of different primers step by step and followed by adjusting the amplification buffer. However, none of the approaches are both time saving and effective enough.

2. Our approach is unique in the utilization of the universal primers in one reaction tube. With a pair of universal primers, the preferential amplification in ordinary multiplex PCR may be avoided. If amplification of one pair of gene-specific primers is inefficient, supplemental amplification would be performed by the universal primers (Fig. 1). The higher the amplification efficiency of gene-specific primers, the less the universal primers participate in the reaction. So the universal primers probably act as a balancer in the novel multiplex PCR, and different targets may be amplified with nearly equal opportunity. In other word, all the primer pairs in a multiplex PCR should allow similar amplification efficiencies for their respective targets. 
3. The universal primer-mediated multiplex PCR has a unique advantage. It makes the optimization of multiplex PCR more straightforward than ever. The concentration of the primers does not need to be adjusted repeatedly to overcome the amplification bias. In this work, all inner primers were with the same concentration, 0.2 $\mu M$. In our laboratory the concentration for gene-specific primers has been used successfully without optimization for over $2 \mathrm{y}$ already. Attention is only paid to the concentration of the universal primer(s), which should be higher than the concentration of the gene-specific primers. In this study the concentration of the universal primers for symmetric multiplex PCR was up to $1 \mu M$, which confirmed that the primers were competitive with gene-specific primers in the reaction and that enough labeled strand was produced for hybridization.

4. At the initial stage of this research on SARS viral RNA detection, only symmetric multiplex PCR was performed. It was puzzling that no hybridization signal was detectable for probe 40 (see [a] in Fig. 5). A PCR reaction was performed in which only the pair of inner primers 40 were used. A sharp and bright band with the predicted size was observed on agarose gel, but no hybridization signal was visible (data not shown). So we excluded the possibility of primer interactions in the multiplex PCR reaction. The PCR product was subsequently sequenced, and no mutation was found (data not shown). At that time we were certain that the problem was loss of hybridization signal. To resolve this problem, asymmetric PCR was taken into account automatically. As expected, when asymmetric multiplex PCR was performed, strong fluorescence signal for probe 40 was obtained on the microarrays.

5. Asymmetric PCR is a powerful tool for generating ssDNA. Without self-annealing, ssDNA hybridization with probes should be more efficient than dsDNA, even if dsDNA is denatured by boiling or alkaline treatment before hybridization. Some researchers have reported that hybridization efficiency was much greater with the single-stranded products compared with to the boiled double-strand PCR products $(41,42)$. In traditional asymmetric PCR, the primer length or concentration is usually out of proportion. However, if several targets are amplified simultaneously by use of those tactics, the outcomes are often disappointing owing to ineffectiveness or nonspecific amplification. By comparison, the novel asymmetric multiplex PCR reported here is preeminent, because only the universal primers are involved during asymmetric amplification. As shown in Fig. 4 [(b), (c), (d) vs (a)], with asymmetric PCR amplification efficiency was no less than with symmetric PCR. Above all, the hybridization signal for probe 40 was on, owing to the asymmetric amplification (Fig. $5[\mathrm{~b}-\mathrm{d}]$ ).

6. Why only probe 40 lost the hybridization signal when symmetric PCR was performed is an interesting problem. We have analyzed the GC content of the sequence for all five inner primer amplicons and discovered that the amplicon hybridizing with probe 40 possesses the highest (49.0\%) GC content. The GC content for other sequences is from 40.9 to $41.9 \%$. As we know, two strands of DNA rich in G and $\mathrm{C}$ will hold to each other more tightly, and they tend to reassociate by themselves after denaturation. This phenomenon may shed partial light on the signal loss for probe 40. Possibly the sequence context of dsDNA also played a role in the signal 
loss. The loss of signal may be pernicious for hybridization analysis because falsenegative results may be reported. The problem could be resolved by using asymmetric amplification whereby ssDNAs are produced. In this study, the detection limit of the microarray assay for symmetric amplification was 10-fold less than that of asymmetric amplification by virtue of the signal loss of probe 40 .

7. Although the asymmetric multiplex PCR reported here works well, a few issues should be kept in mind. The design of the gene-specific primers should comply with the basic principles of conventional multiplex PCR. Special attention to primer design parameters (such as homology of primers with their target nucleic acid sequences, primer length, and GC content) has to be considered $(40,43-47)$, because the overall success of a specific amplification depends on the rate at which primers anneal to their targets, and the rate at which annealed primers are extended along the desired sequence during the early cycles of amplification. The universal primer should be designed to have an appropriate $T_{\mathrm{m}}$ with the gene-specific primers (excluding the universal sequence), to have the least homology with the target nucleic acid sequences, and to avoid the formation of dimmers with the gene-specific primers. Occasionally, even if all these factors are considered, the result may not be the same as predicted owing to the unforeseen interactions of primers. The problem could be solved by changing one of the gene-specific primers.

8. A fluorescence molecule, TAMRA, was labeled to the $5^{\prime}$ end of the universal primers in our study. The hybridization results are in agreement with the asymmetric multiplex PCR results (Table 3 and Fig. 4), so we consider the labeling is adequate for scanning. However, there is a hidden trouble. Some DNA strands produced by the gene-specific primers should also be able to hybridize with the corresponding probes printed on the microarrays, but no fluorescence signal is detectable under these circumstances. To increase the hybridization signal, the gene-specific primers may also be end-labeled.

9. SARS is a serious respiratory illness with significant morbidity and mortality rate (31-37). Its diagnosis depends mainly on the clinical findings of an atypical pneumonia not attributed to any other cause and a history of exposure to a suspect or probable case of SARS, or to the respiratory secretions and other bodily fluids of individuals with SARS. Definitive diagnosis of this novel CoV relies on classic tissue culture isolation, followed by electron microscopy studies to identify the virus in cell culture, which is technically very demanding. Serological testing for increasing titer against SARS-associated CoV was shown to be highly sensitive and specific (32) but was not suitable for quick and early laboratory diagnosis. Molecular tests have also been attempted for the detection of this virus or to confirm infection $(48,49)$. However, only one target was detected in one test using the existing methods, so a higher risk of false negatives was inevitably encountered. Our method is quite different from the existing methods: asymmetric multiplex nested RT-PCR amplification followed by microarray hybridization. The assay was sufficiently sensitive that $10^{\circ}$ copies $/ \mu \mathrm{L}$ viral RNA could be detected. We have used this method to realize the early sensitive detection of SARS virus from clinic samples (unpublished 
work). In actual application, the universal primer uf was omitted. In other words, the ratio of 0:1 for universal primer uf to ur was adopted for efficiency and convenience.

10. In summary, we have established a sensitive and versatile asymmetric multiplex PCR method. Combining with the microarray assay, this method may be applicable in a number of fields, such as identification of microorganisms, detection of the drug-resistant genes, and diagnosis of genetic diseases.

\section{Acknowledgments}

The authors thank Prof. Tao Hung for providing the SARS CoV RNA. We are grateful for the contributions from Hua-fang Gao, Can Wang, Di Jiang, Li Rong, Qing-mei Ma, Hong-li Lu, Tian-tian Cai, Hua-wei Yang, Chuan-zan Zhao, Yan-hua Liu, and Dong Wang.

This work was supported by grants from the National Hi-Tech Program of China, Department of Science and Technology of China (2002AA2Z2011 and 200310230055) and by a grant from the China Postdoctoral Science Foundation (2003034158).

\section{References}

1. Chamberlain, J. S., Gibbs, R. A., Ranier, J. E., Nguyen, P. N., and Caskey, C. T. (1988) Deletion screening of the Duchenne muscular dystrophy locus via multiplex DNA amplification. Nucleic Acids Res. 16, 11141-11156.

2. Sieber, O. M., Lamlum, H., Crabtree, M. D., et al. (2002) Whole-gene APC deletions cause classical familial adenomatous polyposis, but not attenuated polyposis or "multiple" colorectal adenomas. Proc. Natl. Acad. Sci. USA 99, 2954-2958.

3. Moutou, C., Gardes, N., and Viville, S. (2002) Multiplex PCR combining deltaF508 mutation and intragenic microsatellites of the CFTR gene for pre-implantation genetic diagnosis (PGD) of cystic fibrosis. Eur. J. Hum. Genet. 10, 231-238.

4. Zimmermann, K., Schogl, D., Plaimauer, B., and Mannhalter, J. W. (1996) Quantitative multiple competitive PCR of HIV-1 DNA in a single reaction tube. BioTechniques 21, 480-484.

5. Jin, L., Richards, A., and Brown, D. W. (1996) Development of a dual target-PCR for detection and characterization of measles virus in clinical specimens. Mol. Cell. Probes 10, 191-200.

6. Zou, S., Stansfield, C., and Bridge, J. (1998) Identification of new influenza B virus variants by multiplex reverse transcription-PCR and the heteroduplex mobility assay. J. Clin. Microbiol. 36, 1544-1548.

7. Tettelin, H., Radune, D., Kasif, S., Khouri, H., and Salzberg, S. L. (1999) Optimized multiplex PCR: efficiently closing a whole-genome shotgun sequencing project. Genomics 62, 500-507.

8. Druce, J., Catton, M., Chibo, D., et al. (2002) Utility of a multiplex PCR assay for detecting herpesvirus DNA in clinical samples. J. Clin. Microbiol. 40, $1728-1732$. 
9. Robert, P. Y., Traccard, I., Adenis, J. P., Denis, F., and Ranger-Rogez, S. (2002) Multiplex detection of herpesviruses in tear fluid using the "stair primers" PCR method: prospective study of 93 patients. J. Med. Virol. 66, 506-511.

10. Osek, J. (2002) Rapid and specific identification of Shiga toxin-producing Escherichia coli in faeces by multiplex PCR. Lett. Appl. Microbiol. 34, 304-310.

11. Sloan, L. M., Hopkins, M. K., Mitchell, P. S., et al. (2002) Multiplex LightCycler PCR assay for detection and differentiation of Bordetella pertussis and Bordetella parapertussis in nasopharyngeal specimens. J. Clin. Microbiol. 40, 96-100.

12. Harris, E., Kropp, G., Belli, A., Rodriguez, B., andAgabian, N. (1998) Single-step multiplex PCR assay for characterization of New World Leishmania complexes. $J$. Clin. Microbiol. 36, 1989-1995.

13. Strommenger, B., Kettlitz, C., Werner, G., and Witte, W. (2003) Multiplex PCR assay for simultaneous detection of nine clinically relevant antibiotic resistance genes in Staphylococcus aureus. J. Clin. Microbiol. 41, 4089-4094.

14. Oliveira, D. C., and Lencastre, H. H. (2002) Multiplex PCR strategy for rapid identification of structural types and variants of the mec element in methicillinresistant Staphylococcus aureus. Antimicrob. Agents Chemother. 46, 2155-2161.

15. Markoulatos, P., Siafakas, N., and Moncany, M. (2002) Multiplex polymerase chain reaction: a practical approach. J. Clin. Lab. Anal. 16, 47-51.

16. Elnifro, E. M., Ashshi, A. M., Cooper, R. J., and Klapper, P. E. (2000) Multiplex PCR: optimization and application in diagnostic virology. Clin. Microbiol. Rev. 13, 559-570.

17. Henegariu, O., Heerema, N. A., Dlouhy, S. R., Vance, G. H., and Vogt, P. H. (1997) Multiplex PCR: critical parameters and step-by-step protocol, BioTechniques 23, 504-511.

18. Tao, S., and Cheng, J. (2003) Methods and compositions for optimizing multiplex PCR primers. China Patent PCT03/00335.

19. Yershov, G., Barsky, V., Belgovskiy, A., et al. (1996) DNA analysis and diagnostics on oligonucleotide microchips. Proc. Natl. Acad. Sci. USA 93, 4913-4918.

20. Drobyshev, A., Mologina, N., Shik, V., Pobedimskaya, D., Yershov, G., and Mirzabekov, A. (1997) Sequence analysis by hybridization with oligonucleotide microchip: identification of beta-thalassemia mutations. Gene 188, 45-52.

21. Haviv, I., and Campbell, I. G. (2002) DNA microarrays for assessing ovarian cancer gene expression. Mol. Cell. Endocrinol. 191, 121-126.

22. Kim, I. J., Kang, H. C., Park, J. H., et al. (2002) RET oligonucleotide microarray for the detection of RET mutations in multiple endocrine neoplasia type 2 syndromes. Clin. Cancer Res. 8, 457-463.

23. Riccelli, P. V., Merante, F., Leung, K. T., et al. (1994) Hybridization of singlestranded DNA targets to immobilized complementary DNA probes: comparison of hairpin versus linear capture probes. Nucleic. Acids Res. 29, 996-1004.

24. Guo, Z., Guilfoyle, R. A., Thiel, A. J., Wang, R., and Smith, L. M. (1994) Direct fluorescence analysis of genetic polymorphisms by hybridization with oligonucleotide arrays on glass supports. Nucleic. Acids Res. 22, 5456-5465. 
25. Kawai, S., Maekawajiri, S., and Yamane, A. (1993) A simple method of detecting amplified DNA with immobilized probes on microtiter wells. Anal. Biochem. 209, 63-69.

26. Gyllensten, U. B., and Erlich, H. A. (1988) Generation of single-stranded DNA by the polymerase chain reaction and its application to direct sequencing of the HLADQA locus. Proc. Natl. Acad. Sci. USA 85, 7652-7656.

27. Erdogan, F., Kirchner, R., Mann, W., Ropers, H. H., and Nuber, U. A. (2001) Detection of mitochondrial single nucleotide polymorphisms using a primer elongation reaction on oligonucleotide microarrays. Nucleic. Acids Res. 29, E36.

28. Kaltenboeck, B., Spatafora, J. W., Zhang, X., Kousoulas, K. G., Blackwell M., and Storz, J. (1992) Efficient production of single-stranded DNA as long as $2 \mathrm{~kb}$ for sequencing of PCR-amplified DNA. BioTechniques 12, 164-168.

29. Gorelov, V. N., Roher, H. D., and Goretzki, P. E. (1994) A method to increase the sensitivity of mutation specific oligonucleotide hybridization using asymmetric polymerase-chain reaction (PCR). Biochem. Biophys. Res. Commun. 200, 365-369.

30. Scott, D. L., Clark, C. W., Fyffe, A. E., Walker, M. D., and Deah, K. L. (1998) The differentiation of Phytophthora species that are pathogenic on potatoes by an asymmetric PCR combined with single-strand conformation polymorphism analysis. Lett. Appl. Microbiol. 27, 39-44.

31. World Health Organization. (2003) Severe acute respiratory syndrome (SARS). Wkly. Epidemiol. Rec. 78, 81-83.

32. Peiris, J. S., Lai, S. T., Poon, L. L, et al. (2003) Coronavirus as a possible cause of severe acute respiratory syndrome. Lancet 361, 1319-1325.

33. Ruan, Y. J., Wei, C. L., Ee, A. L., et al. (2003) Comparative full-length genome sequence analysis of 14 SARS coronavirus isolates and common mutations associated with putative origins of infection. Lancet 361, 1779-1785.

34. Ksiazek, T. G., Erdman, D., Goldsmith, C. S., et al. (2003) A novel coronavirus associated with severe acute respiratory syndrome. N. Engl. J. Med. 348, 1953-1966.

35. Marra, M. A., Jones, S. J., Astell, C. R., et al. (2003) The genome sequence of the SARS-associated coronavirus. Science 300, 1399-1404.

36. Drosten, C., Gunther, S., Preiser, W., et al. (2003) Identification of a novel coronavirus in patients with severe acute respiratory syndrome. N. Engl. J. Med. 348, 1967-1976.

37. World Health Organization Multicentre Collaborative Network for Severe Acute Respiratory Syndrome (SARS) Diagnosis (2003) A multicentre collaboration to investigate the cause of severe acute respiratory syndrome. Lancet 361, 1730-173.

38. Rota, P. A., Oberste, M. S., Monroe, S. S., et al. (2003) Characterization of a novel coronavirus associated with severe acute respiratory syndrome. Science $\mathbf{3 0 0}$, 1394-1399.

39. Rozen, S. and Skaletsky, H. (2000) Primer3 on the WWW for general users and for biologist programmers. Methods Mol. Biol. 132, 365-386.

40. Shuber, A. P., Grondin, V. J., and Klinger, K. W. (1995) A simplified procedure for developing multiplex PCRs. Genome Res. 5, 488-493. 
41. Kawai, S., Maekawajiri, S., and Yamane, A. (1993) A simple method of detecting amplified DNA with immobilized probes on microtiter wells. Anal. Biochem. 209, 63-69.

42. Guo, Z., Guilfoyle, R. A., Thiel, A .J., Wang, R., and Smith, L. M. (1994) Direct fluorescence analysis of genetic polymorphisms by hybridization with oligonucleotide arrays on glass supports. Nucleic. Acids Res. 22, 5456-5465.

43. Innis, M. A., Gelfand, D. H., Shinsky, J. J., and White, T. J. (eds.) (1989) PCR Protocols: A Guide to Methods and Applications. Academic Press, San Diego, CA.

44. Wu, D. Y., Ugozzoli, L., Pal, B. K., Qian, J., and Wallace, R. B. (1991) The effect of temperature and oligonucleotide primer length on the specificity and efficiency of amplification by the polymerase chain reaction. DNA Cell Biol. 10, 233-238.

45. Dieffenbach, C. W., Lowe, T. M. J., and Dveksler, G. S. (1993) General concepts for PCR primer design. PCR Methods Appl. 3, S30-S37.

46. Mitsuhashi, M. (1996) Technical report: part 2. Basic requirements for designing optimal PCR primers. J. Clin. Lab. Anal. 10, 285-293.

47. Robertson, I. M., and Walsh-Weller, J. (1998) An introduction to PCR primer design and optimisation of amplification reactions. Methods Mol. Biol. 98, 121-154.

48. Zhai, J. M., Briese, T., Dai, E., et al. (2004) Real-time polymerase chain reaction for detecting SARS coronavirus, Beijing, 2003. Emerg. Infect. Dis. 10, 300-303.

49. Yam, W. C., Chan, K. H., Poon, L. L. M., et al. (2003) Evaluation of reverse transcription-PCR assays for rapid diagnosis of severe acute respiratory syndrome associated with a novel coronavirus. J. Clin. Microbiol. 41, 4521-4524. 